\title{
A SMALL-SCALE COMPARATIVE STUDY OF ONLINE HIGHER MUSIC THEORY COURSE AND PRACTICE COURSE
}

\author{
Rui Ma \\ Dr., Beijing City University, China, 13661384500@163.com
}

\begin{abstract}
At the beginning of 2020, affected by the COVID-19 epidemic, the vast majority of higher education in China adopts the form of online teaching. This study collected research materials through questionnaire survey, interview, online teaching platform, and conducted a small-scale comparative study on the music theory course and solfeggio course of music major in Beijing City University. The study investigated the students' learning situation of the two online courses, and compared the differences of learning motivation, learning experience, learning time and learning effect between the two courses. The results indicated that the two courses have obvious differences in students' learning experience, have their own advantages in learning motivation, and have no significant differences in learning duration and academic record. Finally, the implications of this study are also discussed.
\end{abstract}

Keywords: online higher music courses, comparative research, music theory course, music practice course.

\section{INTRODUCTION}

At the beginning of 2020, due to the impact of the epidemic on the normal opening and classroom teaching of colleges and universities, the Ministry of education of China issued a document to guide the organization and management of online teaching in Colleges and universities. China's colleges and universities have successively formulated the relevant methods, arrangements and plans for their own network teaching. Beijing City University has also rapidly formed teaching strategies, established a comprehensive implementation plan, and laid a foundation for the smooth development of teaching. This study focuses on the learning situation of students in this period of online teaching, and whether there are differences in the learning situation of students in two different courses of music theory and solfeggio.

\section{RESEARCH BACKGROUND}

Music theory and solfeggio are both compulsory basic courses for music majors. Both courses started in 2011 when the music major was established, and have experienced continuous improvement and development in nearly 10 years.

Music theory course aims to make students understand the nature of sound, the basic elements of music, the basic law of the combination of sound and sound, master the basic music knowledge and analysis methods including music sound, sound value combination, rhythm, interval, chord and tonality, and have the 
ability of analysis, so as to make full preparation for the study of other theoretical courses . It lays a good foundation for students to learn piano impromptu accompaniment, Chorus Conducting and other courses, and lays a theoretical foundation for comprehensively improving students' comprehensive music ability.

Solfeggio course is the foundation of students' music learning, and is a prerequisite course of harmony, musical form and other courses. The course includes Solfeggio training and dictation training. Through the training, the students can master the listening and visual skills, and closely combine the "visual response to music score" with "auditory feeling from music performance", so that they can have a deeper understanding of music and lay a solid foundation for the professional study of singing and performance.

\section{MAIN SITUATION OF THE COURSES}

\subsection{Main situation of Solfeggio course}

\subsubsection{Study arrangement before class}

The principle of task design before class was auditory preheating and tonality consolidation (Chang, W. C., Su, M. J., Chen, H. S., \& Su, Y. H. , 2008). The preview before class focused on listening and singing of tonal scales and triads. When designing pre class tasks, difficulty and ease were paid special attention. For relatively simple tonality, students could complete many tasks such as preview tonal scale, primary triad, interval dictation, etc.; for relatively difficult tonality, students could listen to the audio in advance and complete the "warm-up" of tonality. In this way, students could not only complete the tasks assigned by teachers through certain efforts, but also naturally gained self-confidence and satisfaction.

\subsubsection{In class teaching design}

Teaching activities in class centered on tonality, gradually and circularly (Dick, W., Carey, L., \& Carey, J., 2010). First of all, the homework of the last class was shared and commented. Through playing the typical mistakes of the students on the UMOOC platform, the reasons for the mistakes were identified; excellent homework was evaluated to create a positive learning atmosphere and make the students clear the goal of their efforts (Zheng Yanlin., 2015). And then, students practice a certain tonal scale, interval, chord, melody, etc., to consolidate their ability and gradually build up their self-confidence.

\subsubsection{Homework arrangement after class}

Homework arrangement after class was based on the consolidation of review, including not only the review of the training content in class, but also the expansion of the content in class(Karen, Swan, and, Daniel, Matthews, \& and, et al., 2012). Through teaching methods and tools, students could understand the main points of practice, learned to use the UMOOC platform to assist their own practice, and gained the satisfaction of "I can sing well" and "I can listen correctly".

\subsection{Main situation of Music theory course}

\subsubsection{Study arrangement before class}

The principle of task design before class was to stimulate interest, preview and feedback Keast, D. A. ., 2009). Therefore, those new learning materials that were close to real life, or those that conflict with students' existing cognition, were selected to attract students' attention and stimulate their interest in learning. Students searched for guidance materials through the Internet, had group discussions with students, consulted the teacher through communication tools, and timely fed back the incomprehensible problems to the teacher, which was conducive to the "targeted" teaching in class.

\subsubsection{In class teaching design}

The design of teaching activities in class was based on the pre class learning tasks (Koehler, M. J., Mishra, P., Hershey, K., \& Peruski, L. ., 2004). Through the design of related learning links, students could fully and deeply understand what they have learned. First of all, the teacher made a review of the completion of pre class tasks, and at the same time, further tested the effect of students' pre class learning. In the teaching of key and difficult knowledge, teachers taught, teachers and students discussed, students discussed in groups, and completed exercises together to promote understanding and strengthen application. The teacher encouraged and affirmed students in time to enhance their confidence in learning.

\subsubsection{Homework arrangement after class}

How to "apply what you have learned" was an important factor to arouse students' learning enthusiasm. After 
class learning mainly included reviewing and summarizing, completing homework, discussing and answering questions. After learning the theory, the students constructed a clear system structure in their mind by combing and summarizing, analyzed and explained the music score by using the theory, and felt the fresh appearance of the theory by listening to the music works. Through "learning for application", students could better experience the fun of learning and the sense of achievement.

\section{THEORETICAL BASIS}

In 1979, John M. Keller, a scholar of Florida State University, first proposed the idea of motivation system design in his book motivation and instructional design: a theoretical perspective. After integrating previous relevant motivation studies, she proposed "ARCS model theory" (Keller, J. M. ., 1983; Visser, L. ., 1990; Song, S. H. ., 1998; Shellnut, B., Knowltion, A. , \& Savage, T. ., 1999). ARCS were derived from the initials of attention, relevance, confidence and satisfaction. Keller put forward a set of strategies and methods to stimulate students' learning motivation based on these four elements. Because of its practicability, operability, effectiveness and good compatibility with the education system(Schartz, S. ., 2014; Na, K. S. , Sirirat, P. , Thanin, R. , \& Zaidatun, T. ., 2018), the theory has been widely concerned and applied by researchers all over the world(Hilal Karakış, Ayşen Karamete, \& Aydın Okçu., 2016; Jorge, Bacca, Silvia, Baldiris, Ramon, \& Fabregat, et al., 2018; Jamil, M. M. , Ningrum, E. , \& Yani, A. ., 2019; Ucar, H. , \& Kumtepe, A. T. ., 2020).

The research on this theory in Chinese academic circles is relatively late. The earliest introduction was in 1997 's "arcs mode of arousing learning motivation and the choice of teaching methods" (Gao liming, 1998). In 2003, Professor Zhang Zuxin, a heavyweight scholar of educational technology in China, pointed out that "up to now, Keller's arcs motivation model is the most systematic theory integrating motivation principles into the process of instructional design" (Zhang Zuxin., 2003), which further pointed out the direction for domestic research. From the beginning of this century, China's related research began to make efforts (Feng, S. L., \& Tuan, H. L., 2005), and from 2011 to 2017, it showed a comprehensive promotion in the depth and breadth of research (Zheng Yanlin, Li Luyi, Xu Rong., 2013; Liu Shuang, Zheng Yanlin, Ruan Shigui., 2015; Yu Qinglan et al., 2015; Jiang libing et al., 2016; Wang Fengge, 2017).

\section{METHOD}

ARCS theory also includes a complete set of research tools - IMMS (instructional materials motivation survey). It includes four dimensions, a total of 36 questions, including 12 attention questions, 9 relevance questions, 9 confidence questions and 6 satisfaction questions. The total reliability of IMMS questionnaire (Keller, 2010) was 0.96 . The reliability indexes of each dimension were $A=0.89, R=0.81, C=0.90, S=$ 0.92. In this study, the Chinese version of IMMS was used to ensure the reliability and validity of the scale (Reinberg, \&amp; Wang wanlei., 2012).

The research focused on questionnaires, interview data and supporting documents. The participants of the study included 37 Music Majors of grade 2019 who took the courses of music theory and solfeggio from February 2020 to June 2021.

37 students were investigated by IMMS questionnaire, and then semi-structured interviews were conducted to understand their learning experience. The data of the questionnaire were sorted out, and the interviews were transcribed and coded. Finally, the supporting documents (including students' online learning data, online homework and discussion, and scores of each stage) were analyzed comprehensively (Bowman, \& Judith, 2014).

\section{DATA ANALYSIS}

\subsection{Learning motivation}

The reliability coefficient of ARCS of Music theory course and Solfeggio course is 0.955 and 0.958 respectively, and the reliability coefficient of each dimension is greater than 0.95 , which indicates that the reliability quality of the whole research data is very high and there is no obvious difference. The two courses have the same values in "sample size" and "maximum", and little difference in "minimum", "average", "standard deviation" and "median". However, the average values of the two courses in the four dimensions of ARCS have their own advantages, as shown in the following table. 
Table 1. ARCS comparison table

\begin{tabular}{|c|c|c|}
\hline Dimension & Music theory course & Solfeggio course \\
\hline Average value of Attention & 3.86 & 3.65 \\
\hline Average value of Relevance & 3.80 & 3.92 \\
\hline Average value of Confidence & 3.25 & 3.63 \\
\hline Average value of Satisfaction & 3.69 & 3.96 \\
\hline
\end{tabular}

\subsection{Learning experience}

There are obvious differences in students' learning experience between the two courses.

Students' feelings about the course of Music theory mainly focused on three aspects: first, the discussion of learning methods, some students think that online learning is convenient, and some students think that offline learning is more efficient; second, about the learning process, many students feel that they have learned new knowledge, rich content, and some students feel that "figured bass" knowledge is more difficult; third, students feel that the "figured bass" knowledge is more difficult Some students feel that they have deepened their understanding of music theory and enriched their knowledge. Some students feel that their new knowledge is of great help to the study of piano and vocal music.

At the same time, students' feelings about Solfeggio mainly focused on the interest of learning. They thought that the online course was interesting, vivid, had a good feeling and had a good time in class.

\subsection{Learning duration}

According to the total number of visits of the following two courses, it can be found that there is little difference in the overall learning time of students in the two courses.

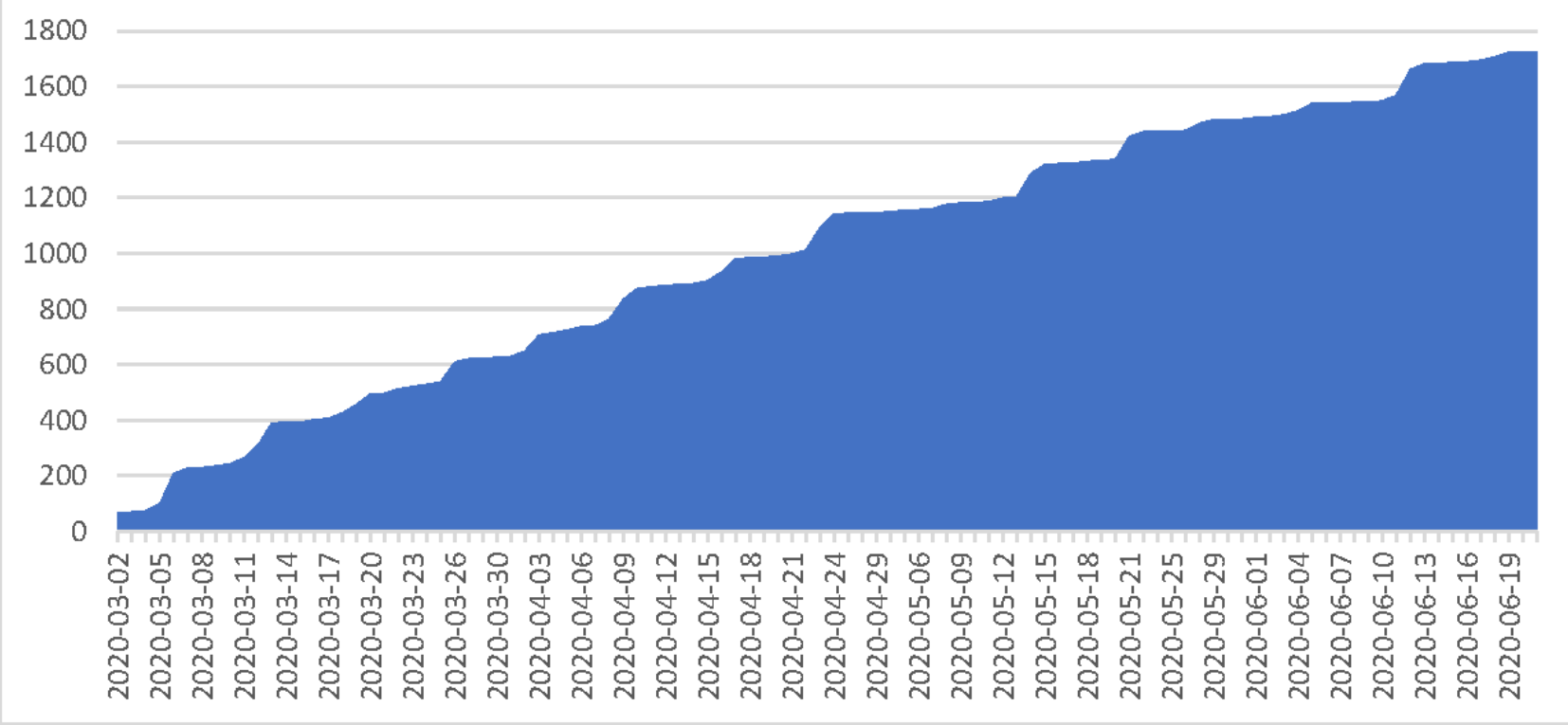

Fig. 1. Total learning duration of Music theory course 
Proceedings of INTCESS 2021 8th International Conference on Education and Education of Social Sciences 18-19 January, 2021

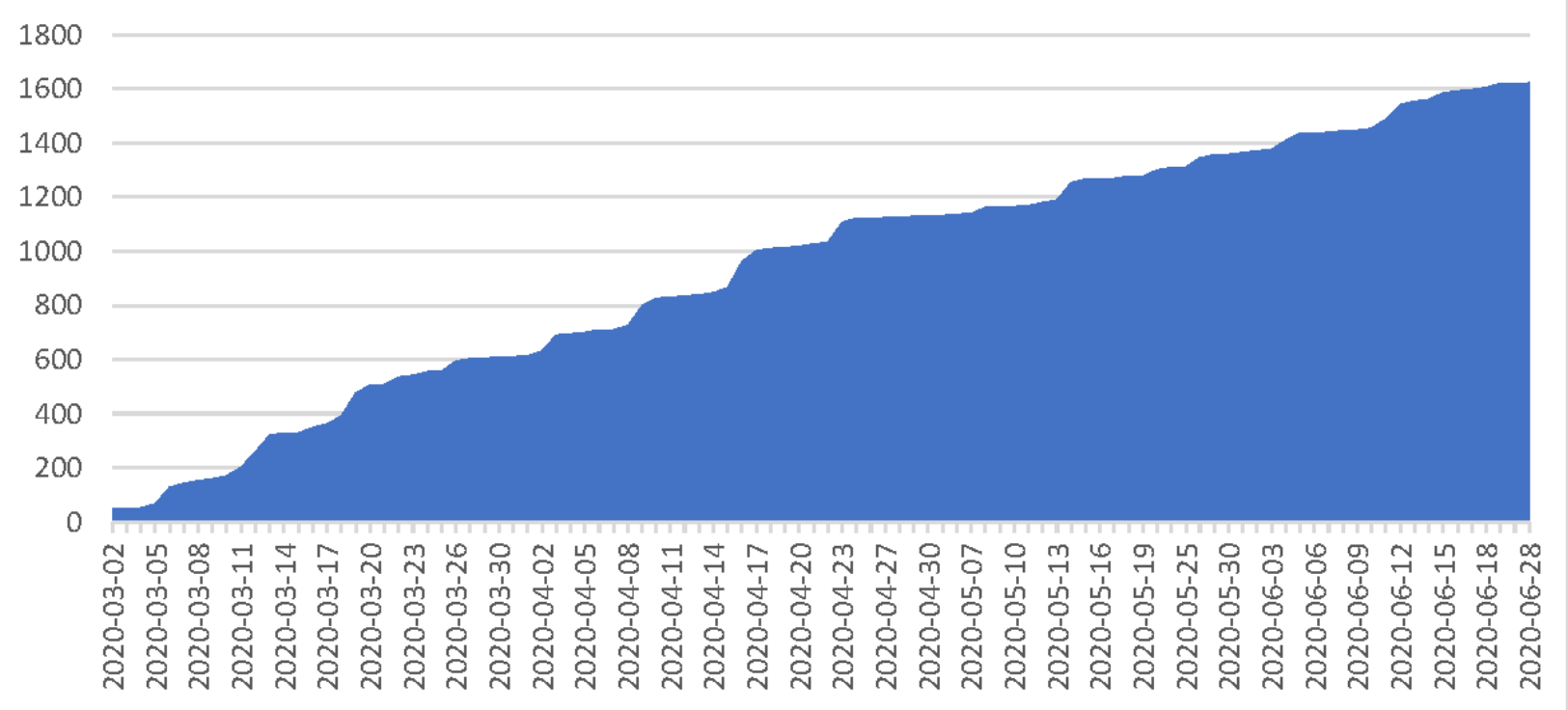

Fig. 2. Total learning duration of Solfeggio course

\subsection{Academic record}

There is little difference between Music theory course and Solfeggio course in students' usual performance, stage assessment, final assessment and general assessment. See the figure below for details:

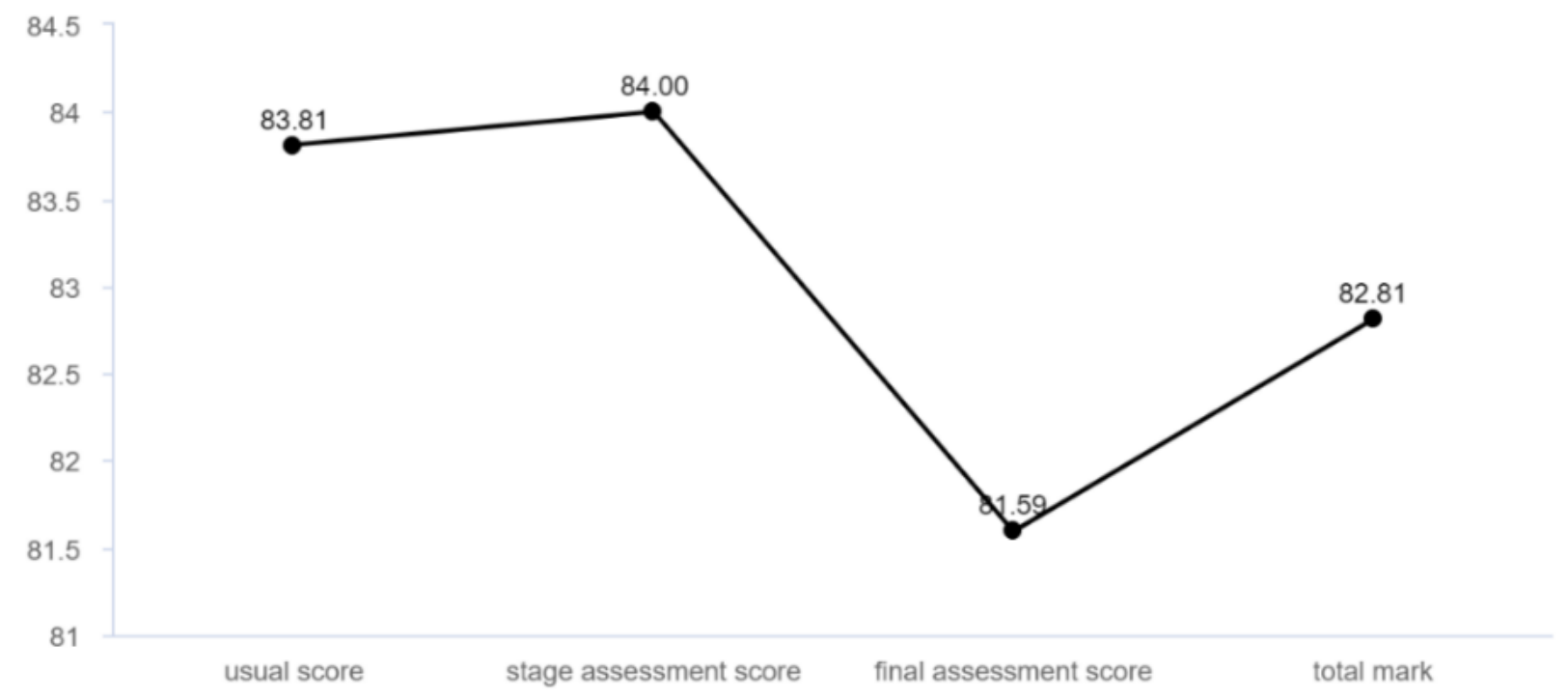

Fig. 3. Scores of Music theory course 


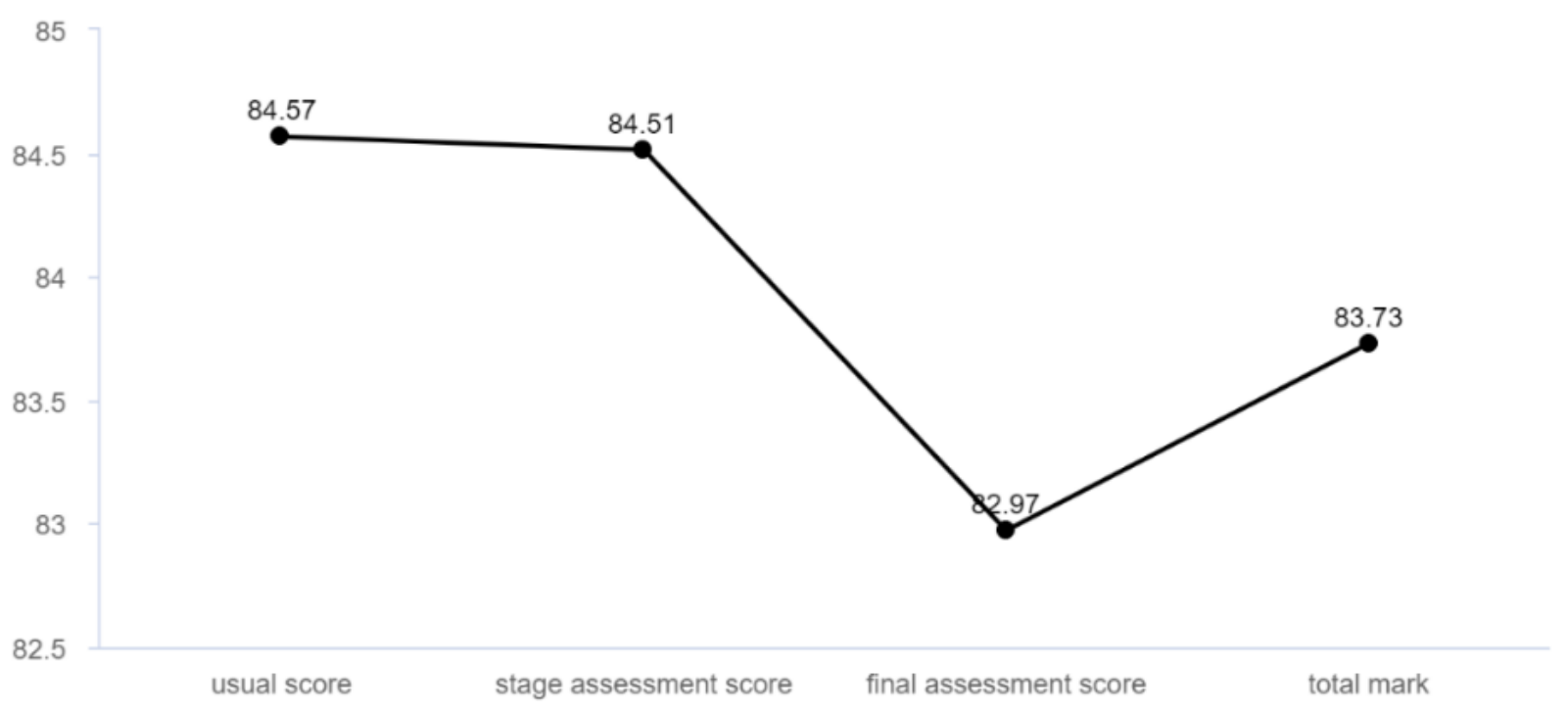

Fig. 4. Scores of Solfeggio course

\section{CONCLUSION AND DISCUSSION}

The two courses have obvious differences in students' learning experience, and have their own advantages in students' learning motivation. There is no significant difference in learning duration and learning effect.

The significance of online teaching should not only be limited to an emergency means, but also become an important part of the future flexible education system (Neuhauser, C. ., 2004). If synchronous online teaching is incorporated into the flexible and open teaching system of higher education in the future, teachers' online teaching literacy needs to be further improved. Due to the rush of teachers during the epidemic period, the limited use of online teaching platform functions, communication tools, writing tools and other technologies and tools, and the lack of awareness of the advantages of online education, such as breaking through the classroom wall, using more abundant online materials, real data, external experts and so on, synchronous teaching is only trying to restore the scene of face-to-face teaching, but it often feels like a lesson The process is limited by the technological environment. In the future, more breakthrough and innovative higher education synchronous online teaching will be the direction of teaching theory and practice research.

\section{LIMITATIONS AND FUTURE STUDIES}

Considering the special period of the epidemic situation, the load pressure of the school's UMOOC platform and the limited network speed and flow of students' Internet access, the curriculum resources built in early 2020 were mainly audio and files, which were convenient for students to open, download and use. In the future, network teaching resources can be further enriched if the network environment allows, and online course teaching in a more comprehensive dimension can be explored.

In the case of sufficient sample size in the future, the study can further explore the correlation between each dimension of arcs and students' performance in each stage.

\section{NOTES ON CONTRIBUTORS}

Dr. Rui Ma is currently a lecturer at the Faculty of Performance, Beijing City University, Beijing, China. Her research interests deal with music curriculum and teaching theory, comparative study of music education and professional development of music teachers.

\section{ORCID}

Rui Ma http://orcid.org/0000-0002-6629-0579 


\section{REFERENCE LIST}

Bowman, \& Judith. (2014). Online learning in music. , 10.1093/acprof:oso/9780199988174.001.0001, 28-54.

Chang, W. C. , Su, M. J., Chen, H. S. , \& Su, Y. H. . (2008). A Study of Moodle Learning Platform on the Internet Online Music Course. Proceedings of the 14th International Conference on Distributed Multimedia Systems, DMS 2008, September 4-6, 2008, Hyatt Harborside Hotel, Boston, Massachusetts, USA. DBLP.

Dick, W. , Carey, L. , \& Carey, J. . (2010). The Systematic Design of Instruction. Higher Education Press.

Feng, S. L. , \& Tuan, H. L. . (2005). Using arcs model to promote 11th graders' motivation and achievement in learning about acids and bases. International Journal of Science \& Mathematics Education, 3(3), 463-484.

Gao Liming. (1998). ARCS model for arousing learning motivation and the choice of teaching methods. Journal of Chongqing Radio and TV University (02), 13-16

Hilal Karakış, Ayşen Karamete, \& Aydın Okçu. (2016). The effects of a computer-assisted teaching material, designed according to the assure instructional design and the arcs model of motivation, on students' achievement levels in a mathematics lesson and their resulting attitudes. European Journal of Contemporary Education, 15(1).

Jamil, M. M. , Ningrum, E. , \& Yani, A. . (2019). Level of learning motivation student based on arcs model on geographic subject. IOP Conference Series: Earth and Environmental Science.

Jorge, Bacca, Silvia, Baldiris, Ramon, \& Fabregat, et al. (2018). Insights into the factors influencing student motivation in augmented reality learning experiences in vocational education and training. Frontiers in psychology, 9, 1486-1486.

Karen, Swan, and, Daniel, Matthews, \& and, et al. (2012). Linking online course design and implementation to learning outcomes: a design experiment. Internet \& Higher Education.

Keast, D. A. . (2009). A constructivist application for online learning in music. Research \& Issues in Music Education, 7(:1), 8.

Keller, J. M. . (1983). Motivational design of instruction. Instructional Design Theories \& Models An Overview of Their Current Status.

Koehler, M. J. , Mishra, P. , Hershey, K. , \& Peruski, L. . (2004). With a little help from your students: a new model for faculty development and online course design. Journal of Technology and Teacher Education, 12(1), 25-55.

Liu Shuang, Zheng Yanlin, Ruan Shigui. (2015). Research on micro curriculum design from the perspective of ARCS model. China Audio Visual Education (2), 51-56

Na, K. S. , Sirirat, P. , Thanin, R. , \& Zaidatun, T. . (2018). Examining the motivation level of students in elearning in higher education institution in thailand: a case study. Education and Information Technologies, 1-21.

Neuhauser, C. . (2004). A maturity model: does it provide a path for online course design?. Journal of Interactive Online Learning, 3(1).

Reinberg, \&amp; Wang wanlei. (2012). Motivational psychology (the practice and Case Analysis series of psychological counseling in national professional counselor Series). Shanghai: Shanghai Academy of Social Sciences Press

Schartz, S. . (2014). The interrelationships of university student characteristics and the keller arcs motivation model in a blended digital literacy course. Dissertations \& Theses - Gradworks, 10(1), 1-12.

Shellnut, B. , Knowltion, A. , \& Savage, T. . (1999). Applying the arcs model to the design and development of computer-based modules for manufacturing engineering courses. Educational Technology Research \& Development, 47(2), 100-110.

Song, S. H. . (1998). The effects of motivationally adaptive computer-assisted instruction developed through the ARCS model. (Doctoral dissertation, The Florida State University).

Ucar, H. , \& Kumtepe, A. T. . (2020). Effects of the arcs- v- based motivational strategies on online learners' 
academic performance, motivation, volition, and course interest. Journal of Computer Assisted Learning, 36.

Visser, L. . (1990). The clinical use of motivational messages : an inquiry into the validity of the arcs model to motivational design. Instructional Science, 19.

Zhang Zuxin. (2003). How to integrate motivation principle into instructional design process -- on Professor John M. Keller's motivation system theory. Open education research, 000 (002), 9-12

Zheng Yanlin, Li Luyi, Xu Rong. (2013). Feedback design of e-learning from the perspective of ARCS model. Modern distance education, (3), 66-71

Zheng Yanlin. (2015). Path selection of MOOC application in Colleges and universities from the perspective of ARCS model. China Audio Visual Education (3), 1-9 